\title{
GESTÃO FLORESTAL NO MARANHÃO: ESTRUTURA ESTADUAL PÓS-DESCENTRALIZAÇÃO
}

\author{
José de Arimatéa Silva ${ }^{1}$, José das Dores de Sá Rocha², Vitor Afonso Hoeflich ${ }^{3}$, \\ Francisco Carneiro Barreto Campello ${ }^{4}$

\begin{abstract}
${ }^{1}$ Universidade Federal Rural do Rio de Janeiro, Departamento de Silvicultura, Seropédica, Rio de Janeiro, Brasil - arimatea@ufrrj.br; ${ }^{2}$ Universidade Federal de Rondônia, Departamento de Engenharia Florestal, Rolim de Moura, Rondônia, Brasil - josedesa @ unir.br

${ }^{3}$ Universidade Federal do Paraná, Departamento de Economia Rural e Extensão, Curitiba, Paraná, Brasil - vitor.ufpr@gmail.com ${ }^{4}$ Ministério do Meio Ambiente, Recife, Pernambuco, Brasil
\end{abstract}

Recebido para publicação: 21/05/2012 - Aceito para publicação: 29/09/2014

\begin{abstract}
Resumo
As instituições dos estados do Nordeste que assumiram a gestão florestal foram diagnosticadas pelo Ministério do Meio Ambiente em 2009. Decorrente deste estudo regional, o presente trabalho tem como objetivos: i) Caracterizar os instrumentos de política e de gestão florestal no estado do Maranhão; ii) Analisar o atual modelo de gestão florestal estadual. Os dados foram obtidos de fontes secundárias na rede mundial de computadores e através da aplicação de questionários em dois Seminários realizados no próprio estado. Os instrumentos de política e gestão florestal foram classificados segundo suas características legais, econômicas e administrativas afetas ao tema. $\mathrm{O}$ modelo de gestão florestal foi analisado com base no modelo de excelência em gestão pública, adaptado para o estudo. As principais conclusões foram: há conflitos legais de competências da gestão florestal no estado, entre a SEMA e a SEAGRO; a SEMA é responsável pela política e pela gestão florestal maranhense; uma Superintendência de Gestão Florestal, ainda não institucionalizada, estava, na prática operando a gestão florestal; planejamento, execução e controle da gestão florestal foram avaliados, de modo geral, em situação insatisfatória, tanto pelo público interno da SEMA quanto pelos seus usuários.

Palavras-chave: Modelo de gestão florestal; descentralização; Nordeste do Brasil.
\end{abstract}

\begin{abstract}
Forest management in the State of Maranhão, beyond decentralization. The institutions in the Northeastern states that assumed forest management were diagnosed by the Ministry of Environment in 2009. Due to this regional study, this paper aims to: i) characterize the fundamentals of policy and forest management in the state of Maranhão, ii) analyze the current model of state forest management. Data were obtained from secondary sources on the World Wide Web and through questionnaires in two seminars held within the state. The fundamentals of policy and forest management were characterized on the basis of legal instruments, administrative and economic sympathetic to the issue. The forest management model was analyzed based on the model of excellence in public management, adapted for the study. The main conclusions were: conflicts of legal jurisdiction in the state of forest management, and between SEAGRO and SEMA.SEMA is responsible for forest management policy and Maranhão, a Superintendent of Forest Management, not yet institutionalized, was in practice the operating forest management, planning, execution and control of forest management were evaluated, in general, an unsatisfactory situation, both the public and internal SEMA by its users.

Keywords: Forest Management model; decentralization; Northeast of Brazil.
\end{abstract}

\section{INTRODUÇÃO}

No transcurso do décimo ano da Conferência das Nações Unidas para o Meio Ambiente e Desenvolvimento (CNUMAD), Vargas (2003) fez uma análise da importância da Agenda 21, resultante dos debates e negociações ocorridos no evento. Para o autor, poucos documentos multilaterais juridicamente não obrigatórios tiveram impacto análogo ao daquele texto. Isso certamente deveu-se, segundo o autor, à amplitude temática e ao enfoque inovador das recomendações nele contidas.

Já no primeiro parágrafo do capítulo 11, sobre combate ao desflorestamento, a Agenda 21 aponta

FLORESTA, Curitiba, PR, v. 45, n. 2, p. 433 - 446, abr. / jun. 2015.

Silva, J. de A. et al.

ISSN eletrônico 1982-4688 / ISSN impresso 0015-3826

433

DOI: $10.5380 /$ rf.v45i2.27078 
uma série de deficiências importantes "nas políticas, métodos e mecanismos" adotados para apoiar e desenvolver os múltiplos papéis ecológicos, econômicos, sociais e culturais das florestas, mas que o texto faz questão de frisar também: de árvores e áreas florestais. O final do parágrafo intitulado "Base para a ação" reforça a necessidade de salvaguardar esses múltiplos papéis das florestas e das áreas florestais por meio de um fortalecimento institucional adequado e apropriado. Este alerta, ressalta o texto, tem sido recorrente em decisões e recomendações de várias entidades das Nações Unidas e de outros círculos (UNITED NATIONS, 1992).

No Anexo III da Agenda 21, que estabelece os princípios sobre florestas, é salientada a soberania dos países para explorar seus recursos em conformidade com suas próprias políticas. Na sua parte final, o preâmbulo recomenda que cada estado aplique os princípios que lista, compartilhando responsabilidades entre os distintos níveis de governo, em conformidade com sua constituição e legislação (UNITED NATIONS, 1992).

Numa leitura circular, retornando-se do anexo para capítulo 11, no seu preâmbulo, este aponta a descentralização como uma das muitas medidas frequentemente exigida para melhorar e harmonizar a formulação de políticas, o planejamento e a programação.

A descentralização da gestão florestal, propugnada no histórico documento de 1992 firmado por 172 países, seria posta em marcha no Brasil quatorze anos mais tarde, com a lei de Gestão de Florestas Públicas (Lei $\mathrm{n}^{\circ}$ 11.284), sancionada em 2 de fevereiro de 2006.Num de seus dispositivos (art. 83), deu nova redação ao artigo 19 do Código Florestal (Lei n ${ }^{\circ}$ 4.771/65), transferindo aos estados da federação a competência para aprovar a exploração de florestas e formações sucessoras, públicas ou privadas. À União remanesceu a competência apenas em relação às áreas sob seu domínio, às unidades de conservação federais e aos empreendimentos de significativo impacto ambiental nacional ou regional (BRASIL, 2006).

Visto que a Lei não estabeleceu nenhuma regra de transição, fixando um prazo para a transferência dessas competências da esfera federal para a estadual, estariam as unidades da federação devidamente aparelhadas para assumir de forma abrupta as novas atribuições?

Visando atenuar, num primeiro momento, as implicações delas decorrentes e contribuir para saná-las numa etapa subsequente, o Ministério do Meio Ambiente realizou um diagnóstico das instituições responsáveis pela gestão florestal nos noves estados da região Nordeste. O estudo, deflagrado a partir do Departamento de Florestas (DEFLOR), da Secretaria de Biodiversidade e Floresta, realizou-se no âmbito do Projeto Demonstrações de Manejo Integrado de Ecossistemas e de Bacias Hidrográficas na Caatinga (MMA/PNUD/GEF/BRA/02/G31, conhecido como GEF-Caatinga), em cujos resultados previstos, um tratava de ações destinadas a fortalecer as instituições de gestão florestal dos estados. Decorrente deste estudo regional mais amplo, o presente trabalho tem como objetivos: i) Identificar e caracterizar os instrumentos de política e de gestão florestal no estado do Maranhão; ii) Caracterizar o modelo de gestão florestal estadual.

\section{MATERIAL E MÉTODOS}

\section{Instrumentos de política florestal}

Husch (1987) esclarece que "uma política florestal de um país é melhor entendida como um sistema de elementos inter-relacionados. Este sistema (ou política) estabelece a forma como um governo executa seus programas florestais e influencia ou controla como a população faz uso de seus recursos florestais". Indica, ainda, que "uma política florestal é um sistema que consiste dos seguintes elementos: 1.78a declaração dos objetivos; 2.um corpo de legislação; 3.a estrutura e a administração de uma organização florestal governamental; 4 .O planejamento, a dotação orçamentária e a execução de programas da organização florestal." Ressalta, igualmente, que "estes elementos formam uma cadeia coerente, ou conforme alguns preferem, uma definição mais limitada de uma política como uma declaração de objetivos ou intenções, então o sistema pode ser dividido ema. as declarações dos objetivos; b. as ações necessárias para alcançar os objetivos."

Schmithüsen (2005) afirma que é possível classificar os instrumentos de políticas de acordo com sua finalidade em relação às esferas de regulamentação pública, a intervenção no mercado, a facilitação do mercado e a persuasão e informação. Merlo e Paveri (1997) classificam os instrumentos de política florestal da seguinte forma: 1. Instrumentos jurídicos e reguladores, 2. Instrumentos financeiros e econômicos, 3. Instrumentos de intervenção no mercado, e 4. Instrumentos de persuasão e de informação.

FLORESTA, Curitiba, PR, v. 45, n. 2, p. 433 - 446, abr. / jun. 2015. 
Para o presente estudo foi considerado como instrumentos de política florestal: os instrumentos legais, administrativos, econômicos e base técnica.

Os instrumentos legais aqui estudados compreendeu o aparato normativo que compreende a constituição, emendas constitucionais, leis complementares, leis especiais (códigos), leis ordinárias, decretos, resoluções, instruções normativas, portarias e ordens de serviço, emitidas pelas instituições políticas, parlamentos e executivos, nos níveis federal e estadual.

Quanto aos instrumentos administrativos foi tomado como o conjunto das instituições, atos e regulamentos, sistemas informacionais, e demais mecanismos institucionais destinados à consecução da política florestal.

Referente aos instrumentos econômicos foi considerado como sendo aqueles que participam dos processos que incidem nos custos e benefícios imputáveis no curso de ação da política florestal. Por último, base técnica abarcou a pesquisa, a ciência e tecnologia geradas pelas instituições de ensino e pesquisa, sob coordenação da política institucional de governo, além dos quadros de recursos humanos e da infraestrutura a elas destinadas.

\section{Gestão pública florestal}

A gestão pública, na acepção de Santos (2006), trata das "funções de gerência pública dos negócios do governo". Por conseguinte, caracteriza o agir do gestor público em três dimensões: i) atos de governo, que diz respeito ao processo político; ii) atos da administração que tratam do cumprimento dos estatutos legais, leis, e; os atos de gestão que engloba os seguintes itens - a) traduzir e implementar a missão, b) fazer o planejamento e controle, c) administrar recursos humanos, materiais, tecnológicos e financeiros, d) ajustar cada unidade organizacional no foco da organização e, e) tomar decisões no âmbito dos conflitos do ambiente interno e externo.

Neste trabalho, a análise foi realizada tomando-se como referência a representação gráfica do modelo de excelência em gestão pública, apresentado por Lima (2007), formatado nos seguintes blocos: A) planejamento (liderança; estratégias e planos; cidadão e sociedade), B) Execução (pessoas, processos), C) Controle (resultados) e D) Ação Corretiva (gestão da informação e do conhecimento). Este modelo foi adaptado para as condições do estudo e os seguintes blocos e respectivos tópicos foram então analisados: Planejamento florestal; Execução (estrutura de gestão florestal, processos administrativos; recursos humanos); Controle (serviço e atendimento público, governança e interação social); Gestão organizacional e normatização.

\section{Coleta de dados e informações}

Os instrumentos legais, econômicos e administrativos foram obtidos em duas etapas: a) busca direta, através da rede mundial de computadores, nos sítios da Secretaria de Estado do Meio Ambiente e Recursos Naturais (SEMA) e da Casa Civil; b) identificação da aplicação dos instrumentos, no estado, mediante entrevista com um dirigente da área florestal ou com um técnico por ele indicado.

As informações e os dados relativos à estrutura de gestão foi obtido a partir de questionários semiabertos (fontes primárias) aplicados: a) aos técnicos do estado que trabalham com recursos florestais, e b) aos usuários diretos do sistema estadual de gestão florestal, além de outros representantes da sociedade. Os questionários foram aplicados em seminários realizados nos dias 16 e 17 de fevereiro de 2009 em São Luís, capital do estado. Intitulado "Seminário Estadual sobre a Descentralização da Política e Gestão Florestal", realizado um para público interno e outro para público externo, ambos os eventos foram promovidos pela própria Secretaria de Estado de Meio Ambiente e Recursos Naturais (SEMA), com o apoio do Projeto GEFCaatinga, especialmente para os propósitos de prover respostas ao diagnóstico que estava em curso. Quanto ao público interno, os questionários foram respondidos, simultaneamente, por profissionais (doze) da Secretaria. E, da mesma forma, por participantes do seminário voltado ao público externo (23 questionários respondidos). Os itens do questionário destinavam-se a obter respostas para três temas principais relativos à questão florestal: planejamento, execução e controle.

O seminário interno foi realizado no auditório da própria SEMA e dele participaram técnicos da Superintendência de Florestas e de outras áreas da Secretaria afetos à gestão florestal; o externo, realizado nas dependências de um hotel da cidade, teve participação de representantes da sociedade civil e de usuários dos serviços da Secretaria. A estes se aplicou um questionário fechado e àqueles um questionário semiaberto, englobando seis temas. De modo a maximizar o tempo dos participantes e motivar todos a responder,

FLORESTA, Curitiba, PR, v. 45, n. 2, p. 433 - 446, abr. / jun. 2015.

Silva, J. de A. et al.

ISSN eletrônico 1982-4688 / ISSN impresso 0015-3826 
folhas-respostas com as alternativas de cada questão foram previamente distribuídas. As questões foram então projetadas, sequencialmente, com o auxílio de um projetor, permitindo que todos assinalassem, simultaneamente, as respostas para cada questão.

$\mathrm{O}$ estudo da capacidade gestora foi realizado convertendo-se as respostas dos questionários para uma escala de 0 a 4, adaptadas a partir da escala de Likert, usada neste tipo pesquisa por Saraph et al. (1989) e Cunha (2007). Calculou-se, então, a porcentagem de cada variável em relação ao número total de repostas, classificando-se a situação conforme expresso na tabela 1.

Tabela 1. Valor escalar e percentual utilizados para classificar as respostas da capacidade de gestão florestal do estado.

Table 1. Scalar value and percentage used to classify the answers of the managerial capacity of the State.

\begin{tabular}{lcc}
\hline Valor escalar & Percentagem & Situação \\
\hline 1 & $0-40$ & Insatisfatória \\
2 & $40,01-60$ & Regular \\
3 & $60,01-80$ & Boa \\
4 & $80,01-100$ & Muito boa \\
\hline Fonte: Autores & &
\end{tabular}

\section{RESULTADOS E DISCUSSÃO}

\section{Identificação dos instrumentos de política e de gestão florestal}

As informações coletadas permitiram identificar instrumentos e política e de gestão florestal segundo as categorias que segue:

Instrumentos legais

A tutela legal dos recursos florestais sob a jurisdição maranhense imprime e reforça os instrumentos legais federais como a Constituição Federal, o Código Florestal e a Política Nacional de Meio Ambiente.

A Carta Maior do Estado do Maranhão assegura a proteção, o uso e a recuperação dos recursos florestais. O seu artigo 239 revela o conteúdo do artigo 225 da Constituição Federal, ao assegurar o meio ambiente ecologicamente equilibrado, bem de uso comum do povo (MARANHÃO, 2001; BRASIL, 1998).

A Constituição Maranhense apresenta, em parte, a mesma estrutura lógica da Constituição Federal relativamente à proteção e uso dos recursos florestais. Inclui o incentivo à produção no bojo da política agrícola e a proteção sob a alçada do meio ambiente. Em alguns aspectos, a Carta Magna Maranhense vai além, ao tratar de particularidades como produção de carvão, babaçuais, recuperação de áreas e criação de conselhos. Estas particularidades poderiam ser pauta de legislação infraconstitucional, uma vez que a Constituição trata de princípios gerais.

A importância social e econômica de espécies vegetais é dinâmica, no tempo e no espaço. Assim, as normas de uso e proteção sobre os babaçuais, o buriti, dentre outras espécies de relevância social, ecológica, econômica devem ser tratadas em atos legais específicos sobre o tema.

As políticas estaduais de meio ambiente e florestal tratam da proteção dos recursos florestais e da promoção ao reflorestamento para atender as demandas de matéria-prima florestal. Todavia, as estruturas dos arcabouços legais de ambos os temas não estão concatenados entre si, e o denso volume de atos legais que os abordam dificulta a interpretação e sua aplicação.

Constatou-se, ainda, a necessidade de instrumento legal que discipline o ordenamento territorial segundo sua vocação e capacidade de suporte dos ecossistemas, fortalecendo a proteção de amostras significativas destes e também a economia local. Este instrumento pode ser definido a partir do zoneamento ecológico econômico, que seja claro e factível de aplicação. Esta proposta é sustentada pela lei de política agrícola (art. 3 da Lei n.8.171/1991) que determina ao estado o papel de planejamento, necessário ao poder público e indicativo para o setor privado. Afirma, ainda, que o estado deve promover, regular, fiscalizar e controlar a produção visando assegurar o abastecimento interno.

Instrumentos administrativos

Salvo aspectos particulares, os instrumentos administrativos revelam relativa abrangência sobre o disciplinamento dos recursos florestais. Trata de aspectos relativos aos recursos florestais, a saber: 
- atenta para uso de recursos de relevância social e econômica para grupos sociais específicos - frágil quanto aos aspectos técnico-normativos de manejo;

- regulamenta algumas atividades florestais - licenciamento, reposição florestal cadastro dos usuários de matéria-prima florestal;

- dispõe de uma estrutura sobre a gestão dos recursos naturais, que compreende: Sistema Estadual de Meio Ambiente - SISEMA; Conselho Estadual de Meio Ambiente - CONSEMA; Sistema de Unidades de Conservação do Maranhão - SUNCMA; Comissão Estadual de Zoneamento Ecológico Econômico CEZEE; Conselho Estadual de Recursos Hídricos - CONERH; Fundo Especial de Meio Ambiente FEMA; Secretaria de Estado de Meio Ambiente e Recursos Naturais - SEMA; Secretaria de Estado de Agricultura e Desenvolvimento Rural - SEAGRO; abriga, no entanto, conflitos de atribuições.

A implementação desses instrumentos revela-se, no entanto, precária.

No que diz respeito à produção de carvão vegetal de origem de florestas plantadas ou nativas, esta já é regulamentada pela própria exigência do Plano de Manejo Florestal, pelo Documento de Origem Florestal e pelo licenciamento de áreas de supressão de vegetação para uso alternativo do solo. Porém, há a necessidade de estabelecer critérios e normas para o manejo dos babaçuais, vez que o fruto da palmeira além de outras utilidades, também é matéria-prima utilizada na produção do carvão, ou seja, há a necessidade de regulamentar os artigos 196 e 200 da Constituição Estadual.

Há carência de regulamentação, e, de efetiva implementação, dos dispositivos legais a seguir elencados:

- $\quad$ programa de reflorestamento de áreas de preservação permanente;

- técnicas e normas sobre o manejo dos babaçuais e outras espécies extrativas;

- Zoneamento Ecológico Econômico - ZEE;

- Sistema de Unidades de Conservação do Maranhão -SUNCMA;

- ações práticas de combate à desertificação;

- desconcentração territorial, instrumentalização e gestão organizacional da SEMA;

- conselho estadual do meio ambiente - CONSEMA;

- conselho estadual sobre política florestal (ou semelhante), e;

- política florestal estadual (abrange todos os itens anteriores).

Os dispositivos legais que disciplinam o uso das florestas são numerosos e desalinhados, o que corrobora para a ineficácia de sua execução.

Instrumentos econômicos

Os instrumentos econômicos de promoção às atividades florestais aqui analisados são aqueles assegurados pelos estatutos legais estaduais e federais, e, no caso destes, se implementados pelo estado através de parcerias.

A Constituição do Estado (art. 197) trata do apoio aos pequenos e médios produtores ao assegurar a criação de instrumentos creditícios e fiscais no âmbito da política agrícola. Uma vez que o órgão formulador de política agrícola abarca a produção agroextrativista e florestal, este instrumento também se aplica à produção florestal, e, portanto, ainda que não tenha sido implementado, subjaz o amparo legal.

O Fundo Estadual de Meio Ambiente, criado na lei que estabelece o Código de Proteção do Meio Ambiente (Lei $\mathrm{n}^{\circ} 5.405$, de 8 de abril de 1992), é um instrumento econômico que atende as finalidades de ações administrativas de comando e controle e recuperação ambiental, mas não contempla, no entanto, o incentivo à produção florestal.

Base técnica

O estado tem regulamentado o dispositivo constitucional sobre assistência técnica e extensão rural, principalmente ao pequeno produtor rural, através da Agência Estadual de Pesquisa Agropecuária e Extensão Rural.

Todavia, este órgão além de não acolher, na prática, a promoção às atividades florestais na sua estrutura organizacional, tem uma cultura organizacional voltada às atividades agrícolas.

O estado dispõe de uma estrutura de ciência e tecnologia que pode ser aproveitada para atuar nas

FLORESTA, Curitiba, PR, v. 45, n. 2, p. 433 - 446, abr. / jun. 2015

Silva, J. de A. et al.

ISSN eletrônico 1982-4688 / ISSN impresso 0015-3826

DOI: $10.5380 /$ rf.v45i2.27078 
demandas de pesquisa e desenvolvimento do setor florestal maranhense. Uma Secretaria de Ciência e Tecnologia, uma Fundação dedicada à pesquisa e desenvolvimento e uma universidade estadual, além de uma universidade federal no estado.

\section{Estrutura de gestão florestal estadual}

A Constituição maranhense dá, previamente, atribuições às Secretarias responsáveis pela administração da produção e proteção florestal. Concede prerrogativa às Políticas Fundiária, Agrícola e Agrária para promover o uso dos recursos naturais de forma racional, como incentivo ao reflorestamento para uso econômico (Seção I e II do Capítulo IV); a proteção dos recursos naturais e florestais é assegurada em capítulo específico (Capítulo IX), a exemplo do que dispõe a Constituição Federal.

Esta concepção sobre uso e proteção dos recursos florestais incorpora o incentivo nas estruturas administrativas, direta e indireta, respectivamente na própria Secretaria de Agricultura, Pecuária e Desenvolvimento Rural (SEAGRO) e na Agência Estadual de Pesquisa Agropecuária e Extensão Rural do Maranhão - AGERP; e a proteção dos recursos florestais ao Meio Ambiente (SEMA). A Lei de Política Florestal (Lei n. 8.528/06) também atribui ao órgão ambiental estadual o licenciamento, a normatização e a fiscalização sobre recursos florestais.

No que diz respeito à secretaria do meio ambiente, vale ressaltar dois pontos: o duplo papel de formulador e executor da SEMA, que é atípico na atual conjuntura da administração pública brasileira nesta área; e o fato de ter uma lei de política florestal, ao invés de diretrizes para política florestal, uma vez a política se consolidada em planos e programas.

\section{Lócus institucional}

O tema florestal tem um duplo endereço, legalmente instituído: SEMA e SEAGRO. A primeira formula e executa a política sobre "meio ambiente e recursos naturais"; a segunda formula, coordena e executa políticas setoriais, além da agrícola, de "extrativismo vegetal, florestal e exploração florestal", contando ainda com uma agência executora destas políticas.

A SEMA tem uma Superintendência de Gestão Florestal (SGF) que trata da questão florestal no âmbito da execução da legislação pertinente ao tema (licenciamento e controle). No entanto, a SEAGRO não abarca na sua estrutura organizacional o tema, ou seja, na prática não trata nem da produção e nem da proteção florestal. No momento do levantamento a SGF estava funcionando de fato, porém ainda não fora legalmente formalizada.

São operacionalizados pela SEMA, como elementos principais da administração florestal: i) o Sistema de Comercialização e Transporte de Produtos Florestais do Estado do Maranhão - Sisflora), ii) o Cadastro de Exploradores e Consumidores de Produtos Florestais do Estado do Maranhão (Ceprof) e iii) o licenciamento de atividades florestais (MARANHÃO, 2006).

\section{Abrangência da estrutura}

Parte da gestão florestal - licenciamento e controle - já está legalmente instituída no âmbito da SEMA. Porém a promoção e o fomento da atividade florestal encontram-se ainda indefinidos. De um lado, a SEAGRO tem, legalmente, essa atribuição; de outro, a SEMA reclama o mesmo para si, no Termo de Cooperação Técnica assinado com o IBAMA. Porém, o reclamo da SEMA sobre tal atribuição é precário em relação à SEAGRO, que tem a atribuição firmada em lei, enquanto que aquela assumiu as atribuições através de um termo de cooperação.

\section{Estrutura e espacialização}

A SEMA dispõe de uma única unidade de atendimento no estado, na capital, São Luís, segundo informações colhidas nos atos legais e verificadas diretamente na Secretaria.

A despeito das duas Secretarias tratarem do tema, o lócus de formulação de política florestal ainda requer um endereço claro, na estrutura organizacional do governo do estado do Maranhão.

\section{Planejamento florestal}

A análise deste e dos temas seguintes tem por base os resultados dos questionários respondidos pelos técnicos da Secretaria envolvidos com a gestão florestal no estado, e pelos atores sociais externos ligados direta e indiretamente ao setor florestal.

O tópico versa sobre o planejamento e estratégias do estado de curto, médio e longo prazos sobre 
o uso e proteção dos recursos florestais, a partir de uma visão de futuro referendada pela sociedade. As questões formuladas procuraram captar a clareza dos instrumentos de implementação e execução do planejamento, em atendimento e harmonização da missão institucional às demandas sociais. Aborda, também, o sistema de planejamento setorial e a participação da sociedade, e a integração ao planejamento geral do estado, assim como seus indicadores de desempenho de política e institucional.

Tabela 2. Respostas dos servidores da SEMA e dos usuários sobre Política e Planejamento Florestal.

Table 2. Responses from servers and users of SEMA on Forest Policy and Planning.

\begin{tabular}{|c|c|}
\hline 1. Servidores & Situação \\
\hline 1.1 Política florestal estadual & Regular \\
\hline 1.2 Instrumentos de implementação e execução da política florestal & Insatisfatória \\
\hline 1.3 Integração entre formulação e execução da política florestal & Insatisfatória \\
\hline 1.4 Mecanismos de participação social na política e planejamento florestal & Insatisfatória \\
\hline 1.5 Integração entre orçamento, planejamento e avaliação do órgão & Insatisfatória \\
\hline 1.6 Integração entre PPA e política florestal & Insatisfatória \\
\hline 1.7 Participação do Órgão no planejamento geral do estado & Insatisfatória \\
\hline 1.8 Relevância do componente florestal no planejamento institucional & Regular \\
\hline 1.9 Integração das diretrizes da política florestal ao planejamento institucional & Insatisfatória \\
\hline 1.10 Internalização do PPA no Órgão Ambiental/Florestal & Regular \\
\hline 1.11 Adoção do planejamento estratégico no Órgão & Insatisfatória \\
\hline 1.12 Qualificação de recursos humanos na área de política e planejamento florestal & Insatisfatória \\
\hline 1.13 Indicadores de desempenho institucional & Insatisfatória \\
\hline 1.14 Gestão orçamentária & Insatisfatória \\
\hline 1.15 Sistema de planejamento & Insatisfatória \\
\hline 2. Usuários & Situação \\
\hline 2.1 Política e planejamento de uso e proteção florestal & Insatisfatória \\
\hline 2.2 Implementação e execução da política florestal & Insatisfatória \\
\hline 2.3 Participação social na política e planejamento florestal & Insatisfatória \\
\hline 2.4 Desempenho da política florestal & Insatisfatória \\
\hline
\end{tabular}

Embora o estado do Maranhão tenha uma lei que estabelece as diretrizes da política florestal, o que lhe atribui uma condição de regular, na avaliação dos servidores do Órgão, sua implementação é majoritariamente insatisfatória (Tabela 2). As informações contidas na tabela 1explicita a atual conjuntura estadual sobre política e planejamento dos recursos florestais. As respostas indicam que este estado precisa construir uma estrutura de planejamento, incluindo um canal de diálogo com a sociedade, e desenvolver uma política florestal, instrumentalizada, de modo a cumprir as suas prerrogativas de coordenador do processo político e atender as aspirações da sociedade.

Execução

Compreende a preparação e capacidade de execução do planejamento. Verifica a organização, a estrutura física e instrumental, segundo suas competências legais, assim como a qualificação, capacitação/treinamento e o conjunto de políticas voltadas à promoção dos recursos humanos que operam o processo e produzem os resultados.

A partir da lei de gestão de florestas públicas (Lei 11.284/06), autorizar a exploração de florestas tanto de domínio público quando privado passou para o âmbito dos estados. Este tópico sintetiza então a situação da estrutura estatal para fazer cumprir a gestão dos recursos florestais, face à nova redação dada ao artigo 19 do Código Florestal.

A tabela 3 expressa a atual situação e nível de institucionalidade quanto ao tema em voga, resultante das macro orientações de Governo. 
Tabela 3. Respostas dos servidores da SEMA e dos usuários sobre a Estrutura de Gestão Florestal.

Table 3. Answers of the servers and users of SEMA on the functions of the State Forest Area.

\begin{tabular}{ll}
\hline 1. Servidores & Situação \\
\hline 1.1 Definição e execução das atribuições da gestão florestal & Regular \\
1.2 Desconcentração - distribuição territorial de agências/balcão de atendimento ao cidadão & Insatisfatória \\
1.3 Infraestrutura física e instrumental necessários à gestão florestal & Insatisfatória \\
1.4 Alocação de recursos humanos segundo as necessidades da gestão florestal & Insatisfatória \\
1.5 Número de servidores na gestão florestal & Insatisfatória \\
1.6 Hierarquização e tomada de decisão & Regular \\
1.7 Internalização e democratização da gestão florestal & Insatisfatória \\
1.8 Leis e normas de uso e proteção dos recursos florestais & Regular \\
1.9 Eficiência na tramitação de processos & Regular \\
1.10 Recursos orçamentários & Regular \\
\hline 2. Usuários & Situação \\
\hline 2.1 Preparação para assumir a gestão florestal & Insatisfatória \\
2.2 Descentralização e relacionamento com os municípios - municipalização da gestão florestal & Insatisfatória \\
2.3 Recursos humanos segundo as necessidades da gestão florestal & Insatisfatória \\
2.4 Capacidade de repostas às demandas de uso e proteção florestal & Insatisfatória \\
2.5 Recursos orçamentários & Insatisfatória \\
\hline
\end{tabular}

Fonte: Autores

Salvo exceções, em que se encontram situações regulares (funcionamento com deficiências), o estado encontra-se altamente deficiente para fazer a gestão dos recursos florestais (Tabela 3).

Os resultados refletem, em parte: a) Conflito de atribuições entre a SEMA e a SEAGRO e AGERP, secretaria de administração das áreas agrícola e pecuária, já evidenciado na tabela $1 ;$ b) Verificação de apenas dois servidores concursados no quadro com formação superior na área de Engenharia Florestal; c) Apenas um escritório de atendimento aos usuários - localizado na capital do estado - para todo o território estadual; d) Falta de equipamentos de uso em perícias técnicas, e; e) Falta de recursos para capacitação/treinamento do quadro técnico, segundo declarações colhidas, em entrevistas, com funcionários e gestores.

O questionário aplicado ao gestor, que não foi respondido, serviria para a complementação e verificação dos itens avaliados pelo público interno e externo.

Gestão de Recursos humanos

O tópico infere sobre o sistema de trabalho, qualificação, capacitação e desenvolvimento da carreira profissional e individual, associados às estratégias da organização, e como esta associação converge para a motivação de cada indivíduo e para o desempenho institucional.

O resultado aponta como boa a qualificação do quadro técnico - formação profissional -, por parte dos servidores; a mesma percepção não é verificada pelos usuários, cujas respostas indicam uma situação apenas regular (Tabela 4).

O item qualificação, quando associado com autonomia no recrutamento, trabalho em equipe e motivação dos servidores mantém o funcionamento mínimo da instituição, face à insuficiência de recursos humanos.

A motivação existente pode ser extraída da força de vontade de um quadro técnico jovem, profissionais que estão entrando no mercado de trabalho, com idade média de 28 anos.

Todavia, esses profissionais adquirem conhecimento do funcionamento da burocracia pública e ingressam no setor privado, devido aos baixos salários e à falta de perspectivas profissionais na instituição. Ademais, a maioria não pertence ao quadro efetivo; assume contratos temporários, o que aumenta a rotatividade. A cada gestão governamental o quadro pode mudar, segundo relatos dos atores internos e externos. A mudança do governo, ocorrida após a coleta dos dados deste trabalho, comprovou este risco. Profissionais que participaram da entrevista informaram, posteriormente, que o governo empossado por medida judicial exonerou parte do quadro profissional da gestão florestal.

Ademais, a debilidade do conjunto das variáveis sobre recursos humanos, plano de carreira funcional, salarial etc., não permitem criar uma cultura organizacional voltada para excelência da gestão pública florestal. A instabilidade do quadro técnico, decorrente das contratações temporárias e das 
condições políticas, acarreta fragilidade institucional. Logo, as atividades e desempenho profissionais acabam sendo influenciados mais pelas "orientações" da direção superior e menos pela missão organizacional.

Tabela 4. Respostas dos servidores da SEMA e dos usuários sobre Recursos Humanos.

Table 4. Responses from servers and users of SEMA on Human Resources.

\begin{tabular}{|c|c|}
\hline 1. Servidores & Situação \\
\hline 1.1 Capacitação/treinamento dos funcionários & Insatisfatória \\
\hline 1.2 Qualificação dos funcionários sobre gestão dos recursos florestais & Boa \\
\hline 1.3 Carreira funcional da administração florestal & Insatisfatória \\
\hline 1.4 Autonomia na contratação/recrutamento de recursos humanos & Regular \\
\hline 1.5 Quadro técnico com formação/atribuição na área de recursos florestais & Insatisfatória \\
\hline 1.6 Qualidade da política de recursos humanos & Insatisfatória \\
\hline 1.7 Qualidade da política salarial & Insatisfatória \\
\hline 1.8 Tomada de decisão e trabalho em equipe & Regular \\
\hline 1.9 Mecanismo de promoção/ascensão profissional meritocrática & Insatisfatória \\
\hline 1.10 Política motivacional dos funcionários & Regular \\
\hline 1.11 Política de avaliação e desempenho & Insatisfatória \\
\hline 1.12 Política de gênero & Insatisfatória \\
\hline 1.13 Infraestrutura adequada às necessidades especiais & Insatisfatória \\
\hline 2. Usuários & Situação \\
\hline 2.1 Capacitação/treinamento dos funcionários & Insatisfatória \\
\hline 2.2 Qualificação dos funcionários sobre gestão dos recursos florestais & Regular \\
\hline 2.3 Política salarial & Insatisfatória \\
\hline 2.4 Mecanismo de promoção/ascensão profissional meritocrata & Insatisfatória \\
\hline 2.5 Política motivacional dos funcionários & Insatisfatória \\
\hline
\end{tabular}

Fonte: Autores

Gestão de Processos Administrativos e de Sistemas de Informações

Compreendem o funcionamento da organização através de suas estruturas físicas, instrumentais e dos processos, segundo suas competências legais definidas, alinhados à missão institucional. O conjunto desses elementos, concatenados e em funcionamento, em iteração com as demais organizações públicas e da sociedade civil, é o fio condutor dos resultados exigidos pela sociedade; e, em decorrência, constitui-se perante ela na identidade da organização.

$\mathrm{Na}$ percepção dos servidores, o cidadão maranhense tem bom conhecimento de qual órgão estadual trata dos recursos florestais, ou seja, a instituição tem uma identidade, segundo evidencia a pesquisa (Tabela 5).

Para os servidores, a instituição não tem conflito de atribuições, porém existe um conflito legal de atribuições entre a SEMA e a SEAGRO e AGERP.

Quanto à missão e às atividades de rotina da organização, ainda que esses elementos não sejam claros para o público externo, os servidores as consideram regulares. Ademais, a estrutura organizacional se encontra em situação insatisfatória para o atendimento da gestão florestal (Tabela 5).

No tocante ao atendimento das necessidades dos usuários, a situação é insatisfatória em todos os aspectos, a instituição até aquele momento dispunha de apenas um local de atendimento para todo o estado. Sistemas de Controle

Versa sobre os mecanismos e meios de mensuração e acompanhamento, interno e externo, de atendimento à satisfação dos receptores dos serviços e ações do estado, sobre o uso e proteção dos recursos florestais. Aponta a satisfação das partes envolvidas, ou seja, os resultados da interação do conjunto da organização com o meio externo. É o produto do que foi planejado e executado no atendimento às demandas da sociedade e à missão institucional.

Serviço e atendimento público

Procura captar a leitura de como o Órgão Ambiental/Florestal está estruturado para atender as necessidades de seus usuários, em cumprimento às suas atribuições institucionais. Permite evidenciar a imagem institucional, quanto à prestação de serviço e demais ações, e o nível de satisfação dos servidores e usuários da instituição. 
Tabela 5. Respostas dos servidores da SEMA e dos usuários sobre Estrutura e Processos Administrativos, e Sistema de Informações.

Table 5. Responses of SEMA servers and users on the Structure and Processes Administrative and Information System.

\begin{tabular}{ll}
\hline 1. Servidores - Estrutura e processos administrativos & Situação \\
\hline 1.1 Identidade institucional & Boa \\
1.2 Missão institucional da gestão florestal & Regular \\
1.3 Definição e execução das atividades e rotinas da gestão florestal & Regular \\
1.4 Conflito de atribuições com outros órgãos & Muito bom \\
1.5 Integração entre atribuições legais e o modelo de gestão & Insatisfatória \\
1.6 Relações interinstitucionais & Regular \\
1.7 Transversalidade da gestão florestal & Insatisfatória \\
1.8 Estrutura organizacional da gestão florestal & Insatisfatória \\
1.9 Descentralização - municipalização da gestão florestal & Insatisfatória \\
\hline 2. Servidores - Sistema de informações & Situação \\
\hline 2.1 Estrutura de tecnologia e informação - TI & Insatisfatória \\
2.2 Capacidade técnica em TI & Insatisfatória \\
2.3 Sistema de dados e informações florestais - SDIF & Insatisfatória \\
2.4 Capacidade técnica operacional do SDIF & Insatisfatória \\
2.5 Dados e informações de uso e proteção florestal disponíveis na internet & Insatisfatória \\
2.6 Uso de instrumentos e meios de TI na gestão organizacional & Insatisfatória \\
\hline 3. Usuários - Estrutura e processos administrativos & Situação \\
\hline 3.1 Infraestrutura física e instrumental necessárias à gestão florestal & Insatisfatória \\
3.2 Desconcentração - distribuição territorial de agências/balcão de atendimento ao cidadão & Insatisfatória \\
3.3 Estrutura organizacional da gestão florestal & Insatisfatória \\
\hline 4. Usuários - Sistema de informações & Situação \\
\hline 4.1 Dados e informações sobre uso e proteção florestal disponíveis na internet & Insatisfatória \\
\hline Fonte: Autores. & \\
&
\end{tabular}

Tabela 6. Respostas dos servidores da SEMA e dos usuários sobre prestação de serviço público e atendimento ao cidadão.

Table 6. Responses from servers and users of SEMA on Service Delivery Public Service and Citizen.

\begin{tabular}{ll}
\hline 1. Servidores & Situação \\
\hline 1.1 Prestação de serviço e atendimento ao cidadão & Regular \\
1.2 Política de atendimento ao cidadão & Insatisfatória \\
1.3 Instrumento de avaliação da prestação dos serviços e atendimento ao cidadão & Insatisfatória \\
1.4 Capacitação/treinamento de atendimento ao cidadão & Regular \\
1.5 Infraestrutura e canal de atendimento ao cidadão & Insatisfatória \\
\hline $\mathbf{2 .}$ Usuários & Situação \\
\hline 2.1 Prestação de serviço e atendimento ao cidadão & Insatisfatória \\
2.2 Infraestrutura e canal de atendimento ao cidadão & Insatisfatória \\
\hline
\end{tabular}

Fonte: Autores.

Embora os servidores considerem como regular a prestação de serviço e o atendimento, os usuários apontaram a situação como insatisfatória (Tabela 6).

Ademais, a organização não tem uma política, com indicadores mensuráveis, de atendimento ao cidadão. Portanto, as interpretações, de ambos os atores, interno e externo, revelam o grau de deficiência institucional e de sua imagem negativa, no âmbito da prestação de serviço e atendimento ao cidadão.

Governança e interação social

São os canais que servem de indicadores e expõe a satisfação das partes envolvidas. Indica o grau de interação intra e interinstitucional com instâncias colegiadas, sindicatos, associações etc. Trata do relacionamento do Governo com os grupos sociais ligados à questão florestal e as ações de política setorial e institucional. 
Tabela 7. Respostas dos servidores da SEMA sobre Redes de Governança.

Table 7. Responses from servers on networks of SEMA Governance.

\begin{tabular}{ll}
\hline 1. Servidores & Situação \\
\hline 1.1 Política sobre ética profissional & Insatisfatória \\
1.2 Política de transparência governamental & Insatisfatória \\
1.3 Política de relações e comunicação interna & Insatisfatória \\
1.4 Política de relações externas & Regular \\
1.5 Gestão participativa & Insatisfatória \\
1.6 Parcerias com a sociedade & Regular \\
\hline 2. Usuários & Situação \\
\hline 2.1 Ética profissional na instituição & Regular \\
2.2 Transparência governamental & Insatisfatória \\
2.4 Relações externas & Regular \\
\hline Fonte: Autoro participativa & Insatisfatória \\
\hline
\end{tabular}

Os resultados revelam a necessidade de se criar meios de participação da sociedade na gestão dos recursos florestais, de forma a melhorar a transparência pública, buscar parcerias, eficiência e eficácia na administração pública florestal, face a atual debilidade institucional (Tabela 7).

Gestão organizacional

Abrange o desempenho do estado, através da liderança da organização, quanto às atribuições, estratégias e metas, processos e pessoas voltados para a eficácia do disciplinamento do uso e proteção dos recursos florestais, segundo os princípios da administração pública.

O desempenho do estado na gestão dos recursos florestais, na maioria dos elementos fundamentais, mostra-se insatisfatório, requerendo, pois, uma melhor estruturação para fazer cumprir seu papel no âmbito da gestão descentralizada, processo efetivamente iniciado com o advento da lei de gestão de florestas públicas (Tabela 8).

Tabela 8. Respostas dos servidores da SEMA sobre Gestão Organizacional e Normatização e Controle.

Table 8. Responses from servers on the of SEMA on Organizational, Standardization and Control Management.

\begin{tabular}{ll}
\hline 1. Servidores - Gestão organizacional & Situação \\
\hline 1.1 Nível de desburocratização & Insatisfatória \\
1.2 Sistema integrado de gestão de processos administrativos & Insatisfatória \\
1.3 Capacitação/treinamento de recursos humanos para a gestão florestal & Insatisfatória \\
1.4 Memória administrativa & Regular \\
1.5 Valores voltados para o serviço público florestal & Regular \\
\hline 2. Servidores - Normatização e controle & Insatisfatória \\
\hline 2.1 Impacto na administração florestal advindo da lei 11.284/06 & Regular \\
2.2 Legislação de uso e proteção dos recursos florestais (clareza e execução) & Insatisfatória \\
2.3 Normatização técnica das atribuições da gestão florestal & Insatisfatória \\
2.4 Padronização e fluxo de processos & Insatisfatória \\
2.5 Agilidade no trâmite das demandas & Situação \\
\hline 3. Usuários - Gestão organizacional & Insatisfatória \\
\hline 3.1 Nível de desburocratização & Insatisfatória \\
3.2 Valores voltados para o serviço público florestal & Situação \\
\hline 4. Usuários - Normatização e controle & Insatisfatória \\
\hline 4.1 Agilidade no trâmite das demandas &
\end{tabular}

\section{CONCLUSÕES}

Referente aos instrumentos de política e gestão florestal chegou-se as seguintes conclusões:

- A tutela jurídica de uso e proteção dos recursos florestais do Maranhão reflete, em parte, as diretrizes nacionais e a Constituição do estado traz especificidades que poderiam ser tratadas em normas infraconstitucionais, o que lhe atribui alicerces para o desenvolvimento dos instrumentos de política

FLORESTA, Curitiba, PR, v. 45, n. 2, p. 433 - 446, abr. / jun. 2015.

Silva, J. de A. et al.

ISSN eletrônico 1982-4688 / ISSN impresso 0015-3826 
florestal.

- O estado dispõe de um conjunto de instrumentos legais e econômicos, e de estruturas administrativas, mas este conjunto revela-se frágil no aspecto operacional e vários são os instrumentos que carecem de regulamentação.

Quanto ao modelo de gestão florestal estadual conclui-se que:

O uso e proteção dos recursos florestais estão atribuídos legalmente a duas Secretarias de Estado, o que na prática provoca sombreamento e lacunas operacionais.

A Secretaria de Estado do Meio Ambiente e Recursos Naturais (SEMA) acumula o papel de formulador e executor de política florestal, mas concentra sua atuação efetiva nas atividades de licenciamento e controle.

O estado do Maranhão não dispõe de uma estrutura autárquica de gestão florestal; esta é feita diretamente pela Secretaria (SEMA), através de uma Superintendência de Gestão Florestal, sequer institucionalizada no momento do levantamento.

O estado não conta ainda com um modelo de gestão florestal stricto sensu; mas apenas de adaptações estruturais para realizar as atribuições da gestão que, por força de lei e do termo de cooperação com o Governo Federal, teve que assumir com o advento da lei de gestão de florestas públicas.

Os conflitos de atribuições institucionais, aliados à falta de planejamento, de recursos humanos do quadro permanente da instituição e à rotatividade dos quadros técnicos fragilizam sobremaneira o já precário arcabouço institucional de gestão dos recursos florestais no estado do Maranhão.

Planejamento, execução e controle da gestão florestal foram avaliados, de modo geral, em situação insatisfatória, tanto pelo público interno da SEMA quanto pelos usuários da mesma.

A importância dos recursos florestais com as finalidades ambientais, sociais e econômicas de amplo reconhecimento local, nacional e internacional permite que sejam elaboradas recomendações visando uma mais transparente e eficaz gestão destes recursos que contemplem as várias funções de gerência pública.

\section{AGRADECIMENTOS}

Os autores expressam seus agradecimentos ao Ministério do Meio Ambiente, que, através da SBF/DEFLOR - e no âmbito do Projeto Demonstrações de Manejo Integrado de Ecossistemas e de Bacias Hidrográficas na Caatinga (MMA/PNUD/GEF/BRA/02/G31), proporcionou a materialidade do estudo e o uso de seus dados e informações para publicações científicas.

\section{REFERÊNCIAS}

BRASIL. Lei n. 11.284, de 2 de março de 2006. Dispõe sobre a gestão de florestas públicas para a produção sustentável. Diário Oficial da União, Brasília, DF, 3 de mar. de 2006. <http://www2.camara.leg.br/legin/fed/lei/2006/lei-11284-2-marco-2006-541235-norma-pl.html>. Acesso em: 31/01/2009.

BRASIL. Lei n. 8.171, de 17 de janeirode 1991.Dispõe sobre a política agrícola. Diário Oficial da União, Brasília, DF, 18 jan. 1991. Disponível em: 〈http://www.planalto.gov.br/ccivil_03/leis/18171.htm>. Acesso em: 31/01/2009.

BRASIL. Constituição da República Federativa do Brasil de 1988. Diário Oficial da União, Brasília, 5 de outubro de 1988. Disponível em: < http://www.planalto.gov.br/ccivil_03/leis/18171.htm>. Acesso em: $31 / 01 / 2009$.

CUNHA, L. M. A. Modelos Rasch e Escalas de Likert e Thurstone na medição de atitudes. $78 \mathrm{f}$. Dissertação (Mestrado em Probabilidades e Estatística) - Departamento de Estatística e Investigação Operacional, Faculdade de Ciências, Universidade de Lisboa, 2007.

HUSCH, B. Guidelines for forest policy formulation. FAO. Forestry Paper, n. 81. Roma. 1987. 88 p. 
LIMA, P. D. B. Excelência em gestão pública: a trajetória e a estratégia do gespública. Rio de Janeiro: Qualitymark, 2007. 248 p.

MARANHÃO. Constituição do Estado do Maranhão.Brasília: Senado Federal, 2001. 236 p.

MARANHÃO. Lei Estadual n. 5.405 de 08 de abril de 1992. Institui o Código de Proteção de Meio Ambiente e dispõe sobre o Sistema Estadual de Meio Ambiente e o uso adequado dos recursos naturais do Estado do Maranhão. Disponível em: 〈http://www.cge.ma.gov.br〉. Acesso em: 31 jan.2009.

MARANHÃO. Lei Estadual n. 8.528 de 07 de dezembro de 2006. Dispõe sobre a Política Florestal e de Proteção à Biodiversidade no Estado do Maranhão. Disponível em:〈http://www.cge.ma.gov.br>. Acesso em: 31 jan.2009.

MERLO, M.; PAVERI, M. Formación y ejecución de políticas forestales: un enfoque sobre la combinación de herramientas de políticas. FAO, XI CONGRESO FORESTAL MUNDIAL. FAO. Antalya, 1997. Disponível em: <http://www.fao.org/forestry/docrep/wfcxi/PUBLI/V5/T32S/1.HTM>, Acessado em 13.01.2008.

SANTOS, C. S. Introdução à Gestão Pública. São Paulo: Saraiva, 2006. 156 p.

SARAPH, J. V.; BENSON, P. G.; SCHOROEDER, R. G. An instrument for measuring the critical factors of quality management. Decision Sciences, v. 20, n. 4, p. 810 - 829,1989.

SCHMITHÜSEN, F. Comprender el impacto transversal de las políticas: aspectos jurídicos y de políticas. In. FAO, Estúdio de Montes, 152. Editado por Yves C. Dubé y Franz Schmithüsen, p. 7 - 50. Roma, 2005.

UNITED NATIONS. Report of the United Nations Conference of Environment and Development,Rio de Janeiro, 3-14 June 1992, Volume I, Resolutions Adopted by the Conference [A/CONF.151/26/Rev.l (Vol. 1)]. 1993. Disponível em: http://daccess-dds-ny.un.org/doc/UNDOC/GEN/N92/836/55/PDF/ N9283655.pdf?OpenElement>. Acesso em: 31 jan.2009.

VARGAS, E. V. A década da Agenda 21. Revista Textos do Brasil. Ed. n. 9.pp. 110-13. Brasília: MRE, 2003. Disponível em:<http://www.dc.mre.gov.br/imagens-e-textos/revista-textos-do-brasil/portugues/ edicao-numero-9>. Acesso em: 07 jul.2007. 
FLORESTA, Curitiba, PR, v. 45, n. 2, p. 433 - 446, abr. / jun. 2015. Silva, J. de A. et al. 